\title{
The prevalence of metabolic-associated fatty liver disease in the Turkish population: A multicenter study
}

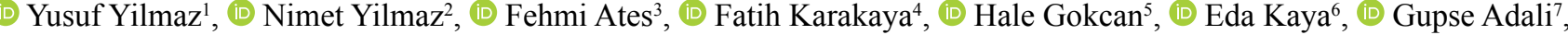 \\ (D) Aysun Caliskan Kartal ${ }^{8}$, (10) Ilker Sen ${ }^{9}$, (1) Emel Ahishali ${ }^{10}$, (1) Seren Ozenirler ${ }^{11}$, (1) Mehmet Koruk ${ }^{12}$, (1) Ahmet Uygun ${ }^{4}$, \\ (D) Ramazan Idilman ${ }^{8}$, Turkish Association for the Study of the Liver (TASL), Fatty Liver Diseases Special Interest Groups
}

\begin{abstract}
${ }^{I}$ Department of Gastroenterology, Marmara University School of Medicine, Istanbul, Turkey; ${ }^{2}$ Division of Gastroenterology, Department of Internal Medicine, SANKO University School of Medicine, Gaziantep, Turkey; ${ }^{3}$ Department of Gastroenterology, Mersin University Faculty of Medicine, Mersin, Turkey; ${ }^{4}$ Department of Gastroenterology, Health Sciences University Gulhane Training and Research Hospital, Ankara, Turkey; ${ }^{5}$ Department of Gastroenterology, Turkish Ministry of Health Ankara City Hospital, Ankara, Turkey; ${ }^{6}$ Department of Internal Medicine, Helios Hospital Schleswig, Academical Educational Hospital of Luebeck and Kiel Universities, Schleswig, Germany; ${ }^{7}$ Department of Gastroenterology, Umraniye Training and Research Hospital, Health Sciences University, Istanbul, Turkey; ${ }^{8}$ Department of Gastroenterology, Ankara University School of Medicine, Ankara, Turkey; ${ }^{9}$ Department of Gastroenterology, Health Sciences University Sisli Hamidiye Etfal Training and Research Hospital, Istanbul, Turkey; ${ }^{10}$ Department of Gastroenterology, Koc University School of Medicine, Istanbul, Turkey;

${ }^{11}$ Department of Gastroenterology, Gazi University School of Medicine, Ankara, Turkey; ${ }^{12}$ Deparment of Gastroenterology, Medical Park Hospital, Gaziantep, Turkey
\end{abstract}

\begin{abstract}
Background and Aim: The objective of the present study was to investigate the prevalence of metabolic-associated fatty liver disease (MAFLD) in patients with dyspepsia.

Materials and Methods: A total of 909 consecutive patients who presented with dyspepsia at 8 tertiary care centers in Turkey between March 2019 and December 2019 were included.

Results: The median age was 47 years. Among them, $30.3 \%$ of the patients were obese, $18.8 \%$ had type 2 diabetes mellitus (T2DM), 35.1\% had metabolic syndrome, $84.8 \%$ had dyslipidemia, and $23.9 \%$ had hypertension. The prevalence of MAFLD was $45.5 \%$. Among the patients with MAFLD, the prevalence of obesity, T2DM, metabolic syndrome, dyslipidemia, and hypertension was $43.3 \%, 24.9 \%, 52.5 \%, 92.3 \%$, and $31.9 \%$, respectively. MAFLD was significantly associated with all of the metabolic comorbidities $(\mathrm{p}<0.001)$. The median Fibrosis-4 Index score of the MAFLD patients was 0.88 (range: $0.1-9.5$ ). Of note, 53 patients with hepatic steatosis did not meet the MAFLD criteria.
\end{abstract}

Conclusion: The results of the present study indicated that there was a significantly high prevalence of MAFLD observed in daily clinical practice in Turkey. Early diagnosis and prevention efforts should be implemented to reduce disease progression, and a region-based strategy is recommended.

Keywords: Metabolic-associated fatty liver disease; non-alcoholic fatty liver disease; type 2 diabetes mellitus.

How to cite this article: Yilmaz Y, Yilmaz N, Ates F, Karakaya F, Gokcan H, Kaya E, et al. The prevalence of metabolic-associated fatty liver disease in the Turkish population: A multicenter study. Hepatology Forum 2021; 2(2):37-42.

Received: December 12, 2020; Accepted: January 18, 2021; Available online: May 21, 2021

Corresponding author: Yusuf Yilmaz; Marmara Universitesi Tip Fakultesi, Gastroenteroloji Anabilim Dali, Istanbul, Turkey

Phone: +90 21677758 50; e-mail: dryusufyilmaz@gmail.com

(1) 0 open access

c) This work is licensed under a Creative Commons Attribution-NonCommercial 4.0 International License.

(C) Copyright 2021 by Hepatology Forum - Available online at www.hepatologyforum.org

\section{Introduction}

Non-alcoholic fatty liver disease (NAFLD) is a group of clinical conditions characterized by the presence of hepatic steatosis in individuals without significant alcohol consumption; the excessive fat in the liver is the result of a secondary cause. The clinicopathological spectrum of NAFLD includes non-alcoholic fatty liver, non-alcoholic steatohepatitis, hepatic fibrosis, cirrhosis, and hepatocellular cancer. NAFLD is commonly associated with metabolic comorbidities, such as obesity, diabetes mellitus, dyslipidemia, and cardiovascular disease. ${ }^{[1]}$

Recently, some studies examined a lack of clarity in the association between NAFLD and metabolic risk factors, and a more appropriate nomenclature for the disease of metabolic (dysfunction)-associated fatty liver disease (MAFLD) has been proposed. ${ }^{[2,3]}$ MAFLD is defined as evidence of hepatic steatosis with invasive or noninvasive methods and the presence of at least 1 of 3 metabolic dysfunctions, such as excess weight or obesity, type 2 diabetes mellitus (T2DM), or evidence of metabolic dysfunction (increased waist circumference and an abnormal glycemic and lipid profile). ${ }^{[2]}$ MAFLD is a heterogeneous entity. Alcohol consumption, regardless of the amount, is not a reference in the diagnosis of MAFLD. Moreover, MAFLD can coexist with other liver diseases. Some studies have reported that MAFLD more accurately reflects the current knowledge of fatty liver diseases associated with metabolic disorders. ${ }^{[2,3]}$ Unlike NAFLD, which requires a negative definition, i.e., a diagnosis of exclusion based on the absence of coexisting chronic liver disorders, MAFLD has a positive definition, and the focus on metabolic factors as causative drivers is expected to reduce patient confusion about disease etiology, which can in turn facilitate patient-physician communication and shared decision-making. ${ }^{[4,5]}$ However, it has also been reported that the MAFLD name change is premature and requires building a wider consensus. ${ }^{[6]}$

The prevalence of NAFLD varies widely; it affects approximately $25 \%$ of individuals across the globe. ${ }^{[7,8]}$ A relatively high prevalence even in apparently healthy Turkish individuals underlines the importance of early recognition of MAFLD in daily clinical practice. ${ }^{\left[{ }^{-12]}\right.}$ Unfortunately, early diagnosis of MAFLD constitutes a major clinical challenge due to its usually asymptomatic presentation. 
Dyspepsia is one of the most prevalent symptoms of gastrointestinal disorders; it affects nearly half of the general population. It is characterized by epigastric pain, burning, or abdominal discomfort. ${ }^{[13]}$ The aim of the present study was to determine the prevalence of MAFLD in patients with dyspepsia in routine clinical practice.

\section{Materials and Methods}

\section{Patients}

This multi-center, prospective cohort study included 932 consecutive patients with a complaint of dyspepsia who presented at 8 tertiary care centers in Turkey between March 2019 and December 2019. Dyspepsia was defined based on the clinical guidelines. ${ }^{[13]}$ All of the patients underwent clinical, laboratory, and radiological examinations. The study data were collected from outpatient visit charts. This study was approved by the ethical committee of University of the Health Sciences (approval numbers: 19/127, 2019/127, approval dates: 26/03/2019, $04 / 09 / 2020)$. This research was funded by the Turkish Association for the Study of the Liver.

The exclusion criteria were the presence of viral hepatitis, drug-induced liver disease, significant alcohol consumption ( $>21$ units of alcohol per week in men and $>14$ units of alcohol per week in women), autoimmune hepatitis, genetic liver disease, or Wilson's disease. Patients with significant transaminase levels that could be explained by liver pathologies other than MAFLD were referred for further diagnosis and excluded from the analysis. Patients with missing data for liver transaminases were also excluded.

\section{Methods}

Serum alanine aminotransferase (ALT), aspartate aminotransferase (AST), gamma glutamyl transpeptidase (GGT), alkaline phosphatase (ALP), bilirubin, fasting glucose, cholesterol, triglycerides, low-density lipoprotein (LDL), high-density lipoprotein (HDL) levels, and a complete blood cell count were measured by a local laboratory at the participating centers.

All of the patients underwent abdominal ultrasonography (US) to rule out any abdominal pathology. The abdominal US was performed by an experienced radiologist who was blinded to the patient's clinical history. Hepatic steatosis was evaluated by comparing the echogenicity of the liver to that of the kidney based on standard criteria and graded as mild, moderate, or severe. Mild fatty liver was defined as slightly diffuse increased echogenicity in the hepatic parenchyma and normal visualization of the diaphragm, hepatic, and portal vein borders. Moderate fatty liver was defined as diffuse increased echogenicity in the hepatic parenchyma with slightly impaired appearance of the intrahepatic vessels and the diaphragm. Severe fatty liver was defined as marked increased echogenicity with poor or no visualization of the intrahepatic vessel borders, the diaphragm, and the posterior right lobe of the liver. ${ }^{[14,15]}$

\section{Definitions}

T2DM was defined based on the American Diabetes Association criteria $^{[16]}$ and metabolic syndrome was defined according to the Adult Treatment Panel III criteria. ${ }^{[17]}$ Dyslipidemia was defined as elevated triglyceride and/or LDL or low HDL levels. ${ }^{[18]}$ Body mass index (BMI) was calculated as weight in kilograms divided by height in meters squared. Obesity was defined based on the World Health Organization

\begin{tabular}{|c|c|}
\hline Characteristics & $\mathrm{n}=909$ \\
\hline Age, years & $47(18-91)$ \\
\hline Gender, male/female & $344(37.8 \%) / 565(62.2 \%)$ \\
\hline $\mathrm{BMI}, \mathrm{kg} / \mathrm{m}^{2}$ & $27.3(15.7-58.8)$ \\
\hline Waist circumference, $\mathrm{cm}$ & $95(41-137)$ \\
\hline Systolic blood pressure, $\mathrm{mm} \mathrm{Hg}$ & 125 (85-189) \\
\hline Diastolic blood pressure, $\mathrm{mm} \mathrm{Hg}$ & $79(50-120)$ \\
\hline Smoker, yes/no & $170(28.0 \%) / 438(72.0 \%)$ \\
\hline Alcohol use, yes/no & $50(5.6 \%) / 848(94.4 \%)$ \\
\hline Platelets, per $\mu \mathrm{L}$ & $260(75-731)$ \\
\hline Type 2 DM, yes/no & $171(18.8 \%) / 738(81.2 \%)$ \\
\hline Hypertension, yes/no & $217(23.9 \%) / 691(76.1 \%)$ \\
\hline Dyslipidemia, yes/no & $687(84.8 \%) / 123(15.2 \%)$ \\
\hline Metabolic syndrome, yes/no & $313(35.1 \%) / 580(64.9 \%)$ \\
\hline Obesity, yes/no & $223(30.3 \%) / 512(69.7 \%)$ \\
\hline MAFLD, yes/no & $414(45.5 \%) / 495(54.5 \%)$ \\
\hline Albumin, mg/dL & $4.3(2.0-6.3)$ \\
\hline AST, U/L & $22(8-196)$ \\
\hline $\mathrm{ALT}, \mathrm{U} / \mathrm{L}$ & $22(2-238)$ \\
\hline GGT, U/L & $24(6-292)$ \\
\hline Fasting blood glucose, $\mathrm{mg} / \mathrm{dL}$ & $95(52-351)$ \\
\hline LDL, mg/dL & $119(24-410)$ \\
\hline $\mathrm{HDL}, \mathrm{mg} / \mathrm{dL}$ & $45(10-231)$ \\
\hline Triglycerides, mg/dL & $129(11-626)$ \\
\hline Insulin, U/L & $9.4(2.03-142.27)$ \\
\hline
\end{tabular}

Continuous data were presented as median (minimum-maximum). BMI: Body mass index; ALT: Alanine aminotransferase; AST: Aspartate aminotransferase; GGT: Gama glutamyl transferase; HDL: High-density lipoprotein; LDL: Lowdensity lipoprotein; MAFLD: Metabolic-associated fatty liver disease.

criteria, with a BMI of $25-29.9 \mathrm{~kg} / \mathrm{m}^{2}$ defined as overweight, and a BMI $\geq 30 \mathrm{~kg} / \mathrm{m}^{2}$ defined as obese. ${ }^{[19]}$

MAFLD was defined as evidence of hepatic steatosis by sonography and the presence of at least 1 of the following 3 criteria:

- $\quad$ BMI $\geq 25 \mathrm{~kg} / \mathrm{m}^{2}$,

- T2DM, or

- At least 2 of the metabolic dysfunction criteria for individuals with a $\mathrm{BMI} \leq 25 \mathrm{~kg} / \mathrm{m}^{2}$.

Metabolic dysfunction indicated the presence of at least 2 of the following criteria: ${ }^{[2,3]}$

1) Waist circumference $\geq 102 / 88 \mathrm{~cm}$ in men and women,

2) Blood pressure $\geq 130 / 85 \mathrm{~mm} \mathrm{Hg}$, or specific drug treatment,

3) Plasma triglyceride level $\geq 150 \mathrm{mg} / \mathrm{dL}$ or specific drug treatment,

4) Plasma HDL level $<40 \mathrm{mg} / \mathrm{dL}$ for men and $<50 \mathrm{mg} / \mathrm{dL}$ for women or specific drug treatment,

5) Prediabetes (i.e., fasting glucose level 100-125 mg/dL, 2-hour postload glucose level 140-199 mg/dL, or glycated hemoglobin 5.7-6.4\%,

6) Homeostasis model assessment-insulin resistance score $\geq 2.5$, or

(7) Plasma high-sensitivity C-reactive protein level $>2 \mathrm{mg} / \mathrm{L} .{ }^{[2]}$

A Fibrosis-4 (FIB-4) Index score was calculated on the day abdominal 
Table 2. Classification of risk for advanced fibrosis according to Fibrosis-4 Index score

\begin{tabular}{|c|c|c|c|c|c|c|}
\hline & \multicolumn{2}{|c|}{$\begin{array}{l}\text { Low risk } \\
\text { FIB-4 }<1.3\end{array}$} & \multicolumn{2}{|c|}{$\begin{array}{c}\text { Indeterminate risk } \\
\text { FIB-4 1.3-2.67 }\end{array}$} & \multicolumn{2}{|c|}{$\begin{array}{c}\text { High risk } \\
\text { FIB-4 }>2.67\end{array}$} \\
\hline & $\mathbf{n}$ & $\%$ & $\mathbf{n}$ & $\%$ & $\mathbf{n}$ & $\%$ \\
\hline Patients with MAFLD $(n=414)$ & 337 & 81.4 & 65 & 15.7 & 12 & 2.9 \\
\hline Patients with evidence of hepatic steatosis $(n=467)$ & 378 & 80.9 & 76 & 16.3 & 13 & 2.8 \\
\hline
\end{tabular}

FIB-4: Fibrosis-4 Index; MAFLD: Metabolic-associated fatty liver disease.

Table 3. Comparison of comorbidity prevalence between patients with MAFLD and NAFLD

\begin{tabular}{lll}
\hline Comorbidity & MAFLD $(\mathbf{n}=\mathbf{4 1 4})$ & NAFLD $(\mathbf{n}=\mathbf{4 6 7})$ \\
\hline Obesity & $159 / 366(43.4 \%)$ & $159 / 386(41.2 \%)$ \\
\hline Type 2 diabetes mellitus & $103 / 414(24.9 \%)$ & $103 / 467(22.1 \%)$ \\
\hline Metabolic syndrome & $217 / 413(52.5 \%)$ & $217 / 466(46.6 \%)$ \\
Dyslipidemia & $360 / 390(92.3 \%)$ & $386 / 430(89.8 \%)$ \\
Hypertension & $132 / 414(31.9 \%)$ & $134 / 467(28.7 \%)$ \\
\hline
\end{tabular}

MAFLD: Metabolic-associated fatty liver disease; NAFLD: Non-alcoholic fatty liver disease.

US was performed using the formula of age (years) $\mathrm{x}$ AST (U/L) / ALT $(\mathrm{U} / \mathrm{L})^{1 / 2} \times$ platelets $\times 10^{9} / \mathrm{L}^{[20]}$ The FIB-4 index yields a value between 0.2 and 10. A score of $<1.3$ indicates a low risk for fibrosis, while a score of $>2.67$ indicates a high risk for advanced fibrosis. ${ }^{[21,22]}$

\section{Statistical Analysis}

The mean and standard deviation, median and range, and frequency and percentage were used as descriptive statistics. Comparisons between 2 groups were assessed using Student's t-test or the Mann-Whitney U test, depending on the distribution of the data. Categorical variables were assessed with a chi-squared test or Fisher's exact test. The normality of distribution was analyzed with the Kolmogorov-Smirnov test. A p value of $<0.05$ was considered statistically significant.

\section{Results}

Of 932 consecutive patients, 9 were excluded due to a significantly elevated transaminase level and were referred for further diagnosis. Another 14 patients were excluded due to missing transaminase level data. A total of 909 patients (male/female: $344 / 565$ ) with dyspepsia were included in the analysis. Most of the patients were female $(62.2 \%)$. The median age was 47 years (range: $18-91$ years). Of the group, $30.3 \%$ of the patients were obese, $18.8 \%$ had T2DM, $35.1 \%$ had metabolic syndrome, $84.8 \%$ had dyslipidemia, $23.9 \%$ had hypertension, $28 \%$ were active smokers, and $5.6 \%$ were social alcohol drinkers. At the time of the evaluation, the median serum AST, ALT, and GGT level was $22 \mathrm{U} / \mathrm{L}$ (range: 8-196 U/L), $22 \mathrm{U} / \mathrm{L}$ (range: 2-238 U/L), and $24 \mathrm{U} / \mathrm{L}$ (range: 6-292 U/L), respectively. The characteristics of the study population are summarized in Table 1. The association between MAFLD and comorbidities is presented in Figure 1.

Sonographic examination revealed hepatic steatosis in 467 patients (51.4\%). Among them, 288 patients $(61.7 \%)$ had mild steatosis, 151 $(32.3 \%)$ had moderate steatosis, and $28(6 \%)$ had severe steatosis.

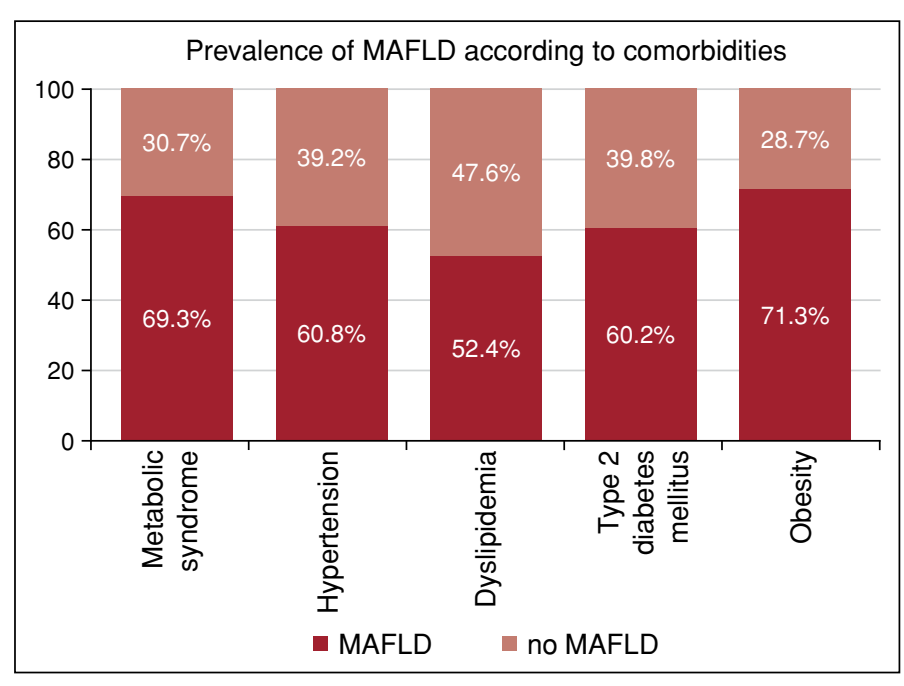

Figure 1. Metabolic-associated fatty liver disease association with comorbidities.

MAFLD: Metabolic-associated fatty liver disease.

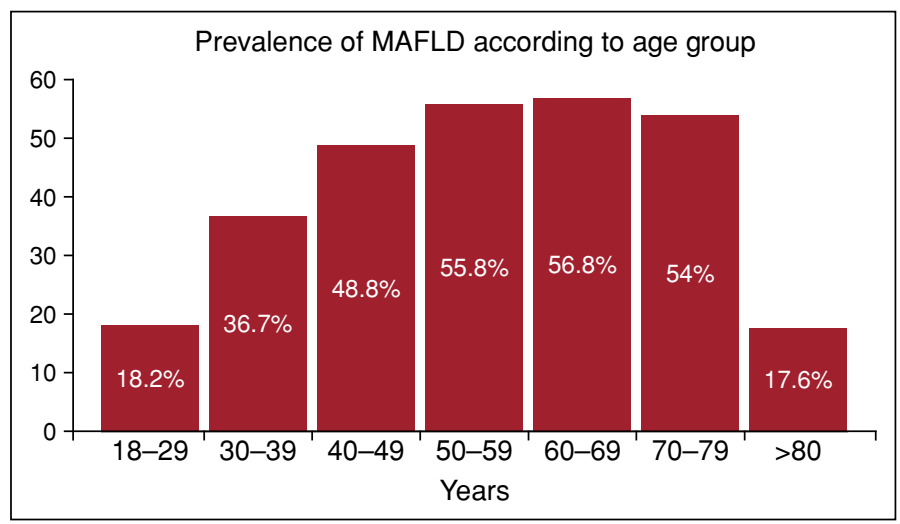

Figure 2. Prevalence of metabolic-associated fatty liver disease according to age group.

The median FIB-4 score of the patients with hepatic steatosis was 0.88 (range: $0.1-9.5)$. A low fibrosis score $(<1.3)$ was observed in $81 \%$ of the patients and $2.8 \%$ presented with high risk for advanced fibrosis (FIB-4 >2.67).

MAFLD was diagnosed in $45.5 \%$ of the 909 dyspeptic patients $(n=414)$ and $88.7 \%$ of the patients with hepatic steatosis. Most of the patients were female $(56.8 \%$ vs. $43.2 \%, \mathrm{p}=0.002)$. MAFLD was most prevalent in the fifth decade of life $(\mathrm{p}<0.001)$. MAFLD was diagnosed in $71.3 \%$ of the obese patients $(\mathrm{p}<0.001), 60.2 \%$ of the diabetic patients 
$(\mathrm{p}<0.001), 69.3 \%$ of the patients with metabolic syndrome $(\mathrm{p}<0.001)$, $60.8 \%$ of the hypertensive patients $(\mathrm{p}<0.001)$, and $52.4 \%$ of the patients with dyslipidemia $(\mathrm{p}<0.001)$. The median FIB-4 score of the patients with MAFLD was 0.88 (range: $0.1-9.5$ ). In all, $81.4 \%$ of the patients had a low fibrosis score, and $2.9 \%$ presented with high risk for advanced fibrosis according to the FIB-4 score. The distribution of MAFLD according to the FIB-4 score and age is summarized in Table 2 and Figure 2, respectively.

The prevalence of metabolic comorbidities in patients with MAFLD and NAFLD is depicted in Table 3.

Of note, 53 dyspeptic patients $(5.8 \%)$ with hepatic steatosis did not meet the MAFLD criteria.

\section{Discussion}

The present study determined the prevalence of MAFLD in patients with dyspepsia at 8 tertiary care centers in Turkey. Half of the dyspeptic patients $(51.4 \%)$ were diagnosed with hepatic steatosis by abdominal US. Interestingly, $38.3 \%$ had moderate and severe steatosis. There was a relatively high presence of comorbid conditions. The prevalence of obesity, T2DM, metabolic syndrome, dyslipidemia, and hypertension was $30.3 \%, 18.8 \%, 35.1 \%, 84.8 \%$, and $23.9 \%$, respectively. These findings are consistent with results reported in previous studies, ${ }^{[7-10]}$ indicating that NAFLD is a growing public health problem worldwide, as well as in Turkey.

The diagnostic approach used for MAFLD plays a significant role in the prediction of prevalence. The diagnostic method chosen can lead to over- or underestimation of the disease. Abdominal US, computerized tomography, magnetic resonance imaging (MRI), controlled attenuation parameter by transient elastography (TE), and MRI-derived proton density fat fraction are noninvasive imaging methods to predict hepatic steatosis. ${ }^{[22-24]}$ Although abdominal US has low sensitivity, it is still routinely and widely used in daily clinical practice due to its availability and cost-effectiveness. ${ }^{[25]}$ In the present study, we found that around half of the dyspeptic patients were diagnosed with MAFLD using abdominal US. Most of the MAFLD patients were female. There was a relationship between the patient's age and the prevalence of MAFLD $(p<0.001)$. The highest prevalence of MAFLD was observed in the fifth decade of life. MAFLD was associated with metabolic disorders. Our findings indicated that more than half of the obese patients, diabetic patients, patients with metabolic syndrome, hypertensive patients, and those with dyslipidemia had a diagnosis of MAFLD.

The increasing prevalence of MAFLD is associated with the increasing prevalence of obesity and T2DM worldwide. ${ }^{[2,3,26]}$ In the present study, the prevalence of obesity and T2DM in dyspeptic patients was $30.3 \%$ and $18.8 \%$, respectively. The obesity rate was not significantly different from 2016 data reported by the World Health Organization of 32.1\%. ${ }^{[19]}$ Epidemiological studies, such as the Turkish Diabetes Epidemiological Study 1 (TURDEP I) ${ }^{[27]}$ and TURDEP II, ${ }^{[28]}$ have found that the prevalence of T2DM increased $90 \%$ over the course of 12 years, impacting $16.5 \%$ of the Turkish population. ${ }^{[27,28]}$ Therefore, we believe the effects of comorbidities have minimized the reported population-based prevalence.

Recent estimation models applied in various countries suggest that in the next decade, the prevalence and the severity of MAFLD will increase worldwide with the increasing rate of comorbidities, such as T2DM, obesity, and metabolic syndrome. ${ }^{[29-31]}$ Region-specific guidelines to effectively manage MAFLD are advisable given the evidence of high rates of these comorbidities in Turkey.
Several noninvasive biochemical-based biomarkers, including the FIB-4 score and imaging methods, such as TE and magnetic resonance elastography are widely used to assess liver fibrosis in routine clinical practice.$^{[32]}$ We calculated a FIB-4 score for the patients with MAFLD to stratify the risk for advanced fibrosis as recommended in the guidelines of European Association for the Study of the Liver and the American Association for the Study of the Liver Diseases. ${ }^{[1,31]}$ The FIB-4 was an appropriate tool to assess the risk of advanced liver fibrosis in our study population since both the FIB4 and NAFLD Fibrosis Score (NFS) have been shown to perform satisfactorily in different clinical settings, including among diabetic and non-diabetic patients as well as patients with elevated and normal transaminase levels. ${ }^{[33,34]}$ However, previous studies also advise that there may be some diagnostic inaccuracies in lean and morbidly obese patients, and patients younger than 35 years or older than 65 years. ${ }^{[35,36]}$ In our study, we chose to calculate a FIB-4 score rather than the NFS. It has been reported that the FIB-4 demonstrated slightly better diagnostic performance compared with the NFS and was clinically more practical since it includes fewer parameters. ${ }^{[34]}$ The diagnostic utility of these tests lies in their ability to exclude patients without advanced fibrosis due to the high negative predictive value. ${ }^{[31,37]}$ In our study, more than $80 \%$ of the study population was classified as low risk for advanced fibrosis. This indicates a need for referral of those remaining $20 \%$ to secondary or tertiary care centers for further diagnostics. ${ }^{[38-40]}$

The primary strength of this study lies in the large cohort sample provided by 8 tertiary care centers in Turkey. We believe our patient selection sufficiently reflects the general population due to the fact that the majority of the patients presented at gastroenterology outpatient clinics with a complaint of dyspepsia without any known liver disease. Moreover, we used a heterogeneous group in terms of comorbidities. Consequently, this study also highlighted the general characteristics of the patient profile of daily routine clinical practice. However, our study must be evaluated in light of its limitations. First, since the dyspeptic patients did not have any symptoms and/or liver test abnormalities, we did not perform a liver biopsy. The severity of liver disease was assessed based on the FIB-4 test. Second, abdominal US examinations were performed by different radiologists at the respective centers. This might have led to some heterogeneity in the sonography findings.

In conclusion, the results of the present study highlight the high prevalence of MAFLD in daily clinical practice. It is expected that the disease burden of MAFLD on the Turkish healthcare system may increase in the future. We recommend the implementation of region-specific guidelines to effectively manage MAFLD.

Ethics Committee Approval: The University of the Health Sciences Clinical Research Ethics Committee granted approval for this study (date: 19/127, 2019/127, numbers: 26/03/2019, 04/09/2020).

Peer-review: Externally peer-reviewed.

Author Contributions: Concept - YY, RI; Design - YY, AU, MK, RI; Supervision - YY, GA, RI; Fundings - YY, NY, FK, IS, GA, ACK, MK, AU, FA, HF, EA, SO, RI; Materials - YY, NY, FK, IS, GA, ACK, MK, AU, FA, HG, EA, SO, RI; Data Collection and/or Processing - YY, NY, FA, FK, HG, EK, GA, ACK, IS, EA, SO, MK, AU, RI; Analysis and/or Interpretation - YY, RI, EK; Literature Search - YY, RI, EK; Writing - YY, RI, EK; Critical Reviews - YY, RI.

Conflict of Interest: The authors have no conflict of interest to declare.

Financial Disclosure: The study was supported by Turkish Association for the Study of the Liver and Fatty Liver Diseases Special Interest Groups. 


\section{References}

1. Chalasani N, Younossi Z, Lavine JE, Charlton M, Cusi K, Rinella M, et al. The diagnosis and management of nonalcoholic fatty liver disease: Practice guidance from the American Association for the Study of Liver Diseases. Hepatology 2018;67(1):328-357. [CrossRef]

2. Eslam M, Newsome PN, Sarin SK, Anstee QM, Targher G, RomeroGomez M, et al. A new definition for metabolic dysfunction-associated fatty liver disease: An international expert consensus statement. J Hepatol 2020;73(1):202-209. [CrossRef]

3. Eslam M, Sarin SK, Wong VW, Fan JG, Kawaguchi T, Ahn SH, et al. The Asian Pacific Association for the study of the liver clinical practice guidelines for the diagnosis and management of metabolic associated fatty liver disease. Hepatol Int 2020;14(6):889-919. [CrossRef]

4. Demirtas CO, Yilmaz Y. Metabolic-associated Fatty Liver Disease: Time to integrate ground-breaking new terminology to our clinical practice? Hepatology Forum 2020;1(3):79-81

5. Yilmaz Y, Byrne CD, Musso G. A single-letter change in an acronym: signals, reasons, promises, challenges, and steps ahead for moving from NAFLD to MAFLD. Expert Rev Gastroenterol Hepatol 2021;15(4):345-352.

6. Younossi ZM, Rinella ME, Sanyal AJ, Harrison SA, Brunt EM, Goodman $Z$, et al. From NAFLD to MAFLD: Implications of a premature change in terminology. Hepatology 2021;73(3):1194-1198. [CrossRef]

7. Kaya E, Yılmaz Y. Non-alcoholic fatty liver disease: A growing public health problem in Turkey. Turk J Gastroenterol 2019;30(10):865-871.

8. Younossi ZM, Koenig AB, Abdelatif D, Fazel Y, Henry L, Wymer M. Global epidemiology of nonalcoholic fatty liver disease-Meta-analytic assessment of prevalence, incidence, and outcomes. Hepatology 2016;64(1):7384.

9. Okur G, Karacaer Z. The prevalence of non-alcoholic fatty liver disease in healthy young persons. North Clin Istanb 2016;3(2):111-117. [CrossRef]

10. Kaya E, Demir D, Alahdab YO, Yilmaz Y. Prevalence of hepatic steatosis in apparently healthy medical students: a transient elastography study on the basis of a controlled attenuation parameter. Eur J Gastroenterol Hepatol 2016;28(11):1264-1267.

11. Mahale AR, Prabhu SD, Nachiappan M, Fernandes M, Ullal S. Clinical relevance of reporting fatty liver on ultrasound in asymptomatic patients during routine health checkups. J Int Med Res 2018;46(11):4447-4454.

12. Bayrak M. Non-invasive diagnosis of nonalcoholic fatty liver disease: impact of age and other risk factors. Aging Male 2020. Doi: 10.1080/13685538.2020.1763293 [Epub Ahead of Print] [CrossRef]

13. Moayyedi P, Lacy BE, Andrews CN, Enns RA, Howden CW, Vakil N. ACG and CAG Clinical Guideline: Management of Dyspepsia. Am J Gastroenterol 2017;112(7):988-1013. [CrossRef]

14. Angulo P. Nonalcoholic fatty liver disease. N Engl J Med 2002;346(16):12211231. [CrossRef]

15. Saadeh S, Younossi ZM, Remer EM, Gramlich T, Ong JP, Hurley M, et al. The utility of radiological imaging in nonalcoholic fatty liver disease. Gastroenterology 2002;123(3):745-750. [CrossRef]

16. American Diabetes Association. Diagnosis and classification of diabetes mellitus. Diabetes Care 2014;37(Suppl 1):S81-90.

17. Grundy SM, Brewer HB Jr, Cleeman JI, Smith SC Jr, Lenfant C; American Heart Association; National Heart, Lung, and Blood Institute. Definition of metabolic syndrome: Report of the National Heart, Lung, and Blood Institute/American Heart Association conference on scientific issues related to definition. Circulation 2004;109(3):433-438. [CrossRef]

18. $2018 \mathrm{AHA} / \mathrm{ACC} / \mathrm{AACVPR} / \mathrm{AAPA} / \mathrm{ABC} / \mathrm{ACPM} / \mathrm{ADA} / \mathrm{AGS} / \mathrm{APhA} / \mathrm{ASPC} /$ NLA/PCNA Guideline on the management of blood cholesterol; A Report of the American College of Cardiology/American Heart Association Task Force on Clinical Practice Guidelines. Circulation 20019;139:e1082-e1143.

19. World Health Organization. NCD risk factors: Overweight / Obesity. Avail- able at: http://www.who.int/gho/ncd/risk_factors/overweight_obesity/obesity_adults/en/. Accessed December 08, 2020.

20. Castera L. Non-invasive tests for liver fibrosis in NAFLD: Creating pathways between primary healthcare and liver clinics. Liver Int 2020;40(Suppl 1):77-81. [CrossRef]

21. Festi D, Schiumerini R, Marzi L, Di Biase AR, Mandolesi D, Montrone $\mathrm{L}$, et al. Review article: the diagnosis of non-alcoholic fatty liver disease -- availability and accuracy of non-invasive methods. Aliment Pharmacol Ther 2013;37(4):392-400. [CrossRef]

22. Kinner S, Reeder SB, Yokoo T. Quantitative Imaging Biomarkers of NAFLD. Dig Dis Sci 2016;61(5):1337-1347. [CrossRef]

23. Grąt K, Grąt M, Rowiński O. Usefulness of Different Imaging Modalities in Evaluation of Patients with Non-Alcoholic Fatty Liver Disease. Biomedicines 2020;8(9):298. [CrossRef]

24. Altamirano J, Qi Q, Choudhry S, Abdallah M, Singal AK, Humar A, et al. Non-invasive diagnosis: non-alcoholic fatty liver disease and alcoholic liver disease. Transl Gastroenterol Hepatol 2020;5:31. [CrossRef]

25. Li Q, Dhyani M, Grajo JR, Sirlin C, Samir AE. Current status of imaging in nonalcoholic fatty liver disease. World J Hepatol 2018;10(8):530-542.

26. Ganz ML, Wintfeld N, Li Q, Alas V, Langer J, Hammer M. The association of body mass index with the risk of type 2 diabetes: a case-control study nested in an electronic health records system in the United States. Diabetol Metab Syndr 2014;6(1):50. [CrossRef]

27. Satman I, Yilmaz T, Sengül A, Salman S, Salman F, Uygur S, et al. Population-based study of diabetes and risk characteristics in Turkey: results of the turkish diabetes epidemiology study (TURDEP). Diabetes Care 2002;25(9):1551-1556. [CrossRef]

28. Satman I, Omer B, Tutuncu Y, Kalaca S, Gedik S, Dinccag N, et al; TURDEP-II Study Group. Twelve-year trends in the prevalence and risk factors of diabetes and prediabetes in Turkish adults. Eur J Epidemiol 2013;28(2):169-180. [CrossRef]

29. Alswat K, Aljumah AA, Sanai FM, Abaalkhail F, Alghamdi M, Al Hamoudi WK, et al. Nonalcoholic fatty liver disease burden - Saudi Arabia and United Arab Emirates, 2017-2030. Saudi J Gastroenterol 2018;24(4):211-219.

30. Swain MG, Ramji A, Patel K, Sebastiani G, Shaheen AA, Tam E, et al. Burden of nonalcoholic fatty liver disease in Canada, 2019-2030: a modelling study. CMAJ Open 2020;8(2):E429-E436. [CrossRef]

31. European Association for the Study of the Liver (EASL); European Association for the Study of Diabetes (EASD); European Association for the Study of Obesity (EASO). EASL-EASD-EASO Clinical Practice Guidelines for the management of non-alcoholic fatty liver disease. J Hepatol 2016;64(6):1388-1402. [CrossRef]

32. Ismaiel A, Leucuta DC, Popa SL, Fagoonee S, Pellicano R, Abenavoli L, Dumitrascu DL. Non-invasive biomarkers in predicting non-alcoholic steatohepatitis and assessing liver fibrosis: systematic review and meta-analysis. Panminerva Med 2020. Doi: 10.23736/S0031-0808.20.04171-3 [Epub Ahead of Print]

33. Alkayyali T, Qutranji L, Kaya E, Bakir A, Yilmaz Y. Clinical utility of noninvasive scores in assessing advanced hepatic fibrosis in patients with type 2 diabetes mellitus: a study in biopsy-proven non-alcoholic fatty liver disease. Acta Diabetol 2020;57(5):613-618. [CrossRef]

34. Kaya E, Bakir A, Eren F, Yilmaz Y. The utility of noninvasive scores in non-alcoholic fatty liver disease patients with normal and elevated serum transaminases. Hepatology Forum 2020;1(1):8-13. [CrossRef]

35. Eren F, Kaya E, Yilmaz Y. Accuracy of Fibrosis-4 index and non-alcoholic fatty liver disease fibrosis scores in metabolic (dysfunction) associated fatty liver disease according to body mass index: failure in the prediction of advanced fibrosis in lean and morbidly obese individuals. Eur J Gastroenterol Hepatol 2020. Doi: 10.1097/MEG.0000000000001946 [Epub Ahead of Print] [CrossRef] 
36. McPherson S, Hardy T, Dufour JF, Petta S, Romero-Gomez M, Allison M, et al. Age as a confounding factor for the accurate non-invasive diagnosis of advanced NAFLD fibrosis. Am J Gastroenterol 2017;112(5):740-751.

37. Kaya E, Bakir A, Kani HT, Demirtas CO, Keklikkiran C, Yilmaz Y. Simple noninvasive scores are clinically useful to exclude, not predict, advanced fibrosis: a study in turkish patients with biopsy-proven nonalcoholic fatty liver disease. Gut Liver 2020;14(4):486-491. [CrossRef]

38. Jafarov F, Kaya E, Bakir A, Eren F, Yilmaz Y. The diagnostic utility of fibrosis-4 or nonalcoholic fatty liver disease fibrosis score combined with liver stiffness measurement by fibroscan in assessment of advanced liver fibrosis: a biopsy-proven nonalcoholic fatty liver disease study. Eur J Gastroenterol Hepatol 2020;32(5):642-649. [CrossRef]

39. Yilmaz Y, Kaya E, Eren F. Letter: the use of Fibrosis-4 score in primary care and diabetology practices-Occam's razor applied to advanced fibrosis screening. Aliment Pharmacol Ther 2020;52(11-12):1759-1760.

40. Younossi ZM, Corey KE, Alkhouri N, Noureddin M, Jacobson I, Lam B, et al; US Members of the Global Nash Council. Clinical assessment for high-risk patients with non-alcoholic fatty liver disease in primary care and diabetology practices. Aliment Pharmacol Ther 2020;52(3):513526. [CrossRef] 